\title{
Brain activation in paediatric obsessive-compulsive disorder during tasks of inhibitory control
}

\author{
James Woolley, Isobel Heyman, Mick Brammer, Ian Frampton, Philip K. McGuire and Katya Rubia
}

\section{Background}

Obsessive-compulsive disorder (OCD) may be related to a dysfunction in frontostriatal pathways mediating inhibitory control. However, no functional magnetic resonance imaging (fMRI) study has tested this in children.

\section{Aims \\ To test whether adolescents with OCD in partial remission would show abnormal frontostriatal brain activation during tasks of inhibition.}

\section{Method}

Event-related fMRI was used to compare brain activation in 10 adolescent boys with OCD with that of 9 matched controls during three different tasks of inhibitory control.

\section{Results}

During a 'stop' task, participants with OCD showed reduced activation in right orbitofrontal cortex, thalamus and basal ganglia; inhibition failure elicited mesial frontal underactivation. Task switching and interference inhibition were associated with attenuated activation in frontal, temporoparietal and cerebellar regions.

\section{Conclusions}

These preliminary findings support the hypothesis that paediatric OCD is characterised by a dysregulation of frontostriatothalamic brain regions necessary for motor inhibition, and also demonstrate dysfunction of temporoparietal and frontocerebellar attention networks during more cognitive forms of inhibition.

\section{Declaration of interest}

None. Funding detailed in Acknowledgements.
In adult obsessive-compulsive disorder (OCD) there is evidence of abnormalities in inhibitory functions such as motor and interference inhibition and task switching, ${ }^{1,2}$ as well as in mediating frontostriatothalamic networks. ${ }^{3-5}$ These deficits have been associated with poor inhibitory control of obsessions and compulsions. ${ }^{3}$ Although OCD usually begins in childhood, ${ }^{6}$ there has been no functional imaging study in paediatric OCD. We used event-related functional magnetic resonance imaging (fMRI) to test for frontostriatal dysfunction in adolescents with OCD compared with matched controls during three different tasks of inhibitory control ('stop', motor Stroop and 'switch' tasks) that activate task-specific frontostriatal brain regions. ${ }^{7,8}$ In order to minimise the impact of concurrent anxiety, ritualising or the potential need to inhibit obsessions or compulsions during the scanning procedure, we studied adolescents with treated OCD who had minimal residual symptoms. Impaired inhibitory performance in adult OCD is still observed despite treatment and symptom reductions. ${ }^{9}$ Our hypothesis therefore was that brain abnormalities during inhibitory control are a trait marker of OCD and would still be observed in adolescents whose disorder was in partial remission.

\section{Method}

\section{Participants}

Ten boys aged 12-16 years were recruited to the study from the Maudsley Hospital child and adolescent OCD clinic. All had a clinical diagnosis of obsessive-compulsive disorder, with a mean pretreatment score on the Children's Yale-Brown Obsessive Compulsive Scale $(\text { CY-BOCS })^{10}$ of 20.5 (range 12-33). Assessment with this scale was repeated before fMRI scanning and confirmed significant symptomatic improvement (mean $46 \%$ for obsessions and $49 \%$ for compulsions). Some residual symptoms were present in all 10 boys at scanning (mean total CY-BOCS score 11, range 2-21), so all could be characterised as treatment responders.
Predominant symptom subtypes were washing and checking. To avoid potential state effects of anxiety and depression, additional inclusion criteria were scores below 15 on the Birleson depression questionnaire ${ }^{11}$ and scores below 19 on the Revised Children's Manifest Anxiety Scale (R-CMAS). ${ }^{12}$ Exclusion criteria included a history of a general or specific intellectual disability or psychiatric disorders, in particular comorbid tic disorders (including Tourette syndrome), autism-spectrum disorder, attentiondeficit hyperactivity disorder, affective disorders or other anxiety disorders, assessed using the Child Behavior Checklist ${ }^{13}$ and by an experienced psychiatrist (I.H.). Symptom scores and illness duration (at the time of first presentation to the specialist clinic) are shown in Table 1 . The majority of participants in the OCD group $(n=8)$ were being treated with a selective serotonin reuptake inhibitor (SSRI), with a mean duration of treatment of 5 months (range 2-12); five patients had completed a course of cognitive-behavioural therapy (mean eight sessions, range four to ten). The control group comprised nine healthy volunteer male adolescents screened using the Child Behavior Checklist and the CY-BOCS. They were matched for verbal IQ, handedness, age and socio-economic background (see Table 1). The study was approved by the local ethics committee and after complete description of the study to the adolescents and parents, written informed consent or assent was obtained for all participants.

\section{Experimental design}

The tasks were presented in fixed order (stop, motor Stroop, switch), using a video projector within the MRI scanner, and behavioural response data were recorded. All participants were trained once on each task and acclimatised to the scanning environment in advance. Randomised presentation, mixed trial, rapid event-related fMRI designs were used with jittered inter-trial intervals and random events to optimise statistical efficiency. 


\section{Stop task}

The fMRI adaptation of the 6 min tracking 'stop' task ${ }^{8,14}$ measures the ability to suppress an already triggered motor response. The basic task is a choice reaction time test with a mean inter-trial interval of $1.8 \mathrm{~s}$. In $20 \%$ of trials the 'go' signals were followed (about $250 \mathrm{~ms}$ later) by 'stop' signals, and participants had to inhibit their motor responses. A tracking algorithm changed the time interval between go-signal and stop-signal onsets according to each individual's performance in order to provide $50 \%$ successful and $50 \%$ unsuccessful inhibition trials. Brain activation related to successful inhibition was measured in the contrast of brain activation to the $50 \%$ successful inhibition trials with that of the $50 \%$ of unsuccessful stop trials (successful stop minus unsuccessful stop trials). Brain activation related to inhibition failure was measured in the contrast of the $50 \%$ unsuccessful stop trials with the successful go trials (thus controlling for the motor response). ${ }^{8,14}$

\section{Motor Stroop task}

The 6 min motor Stroop task ${ }^{7}$ involves a stimulus-response spatial incompatibility effect, or 'Simon effect', reflected in a slowed reaction time to incongruent as compared with congruent trials. Participants have to press a left or right button depending on whether a congruent arrow signal of $300 \mathrm{~ms}$ indicating left or right appears either on the left or right side of the screen (mean intertrial interval $1.8 \mathrm{~s}$ ). In $12 \%$ of incongruent trials arrows appeared on the side opposite to where they point. Participants have to inhibit responding according to the interfering, predominant spatial information in order to execute the response to the iconic information. The event-related fMRI analysis subtracts the successfully performed congruent from successfully performed incongruent Stroop trials (incongruent minus congruent). ${ }^{7}$

\section{Switch task}

A modified version of the Meiran switch task was used, ${ }^{7}$ requiring cognitive switching between two spatial dimensions. A target dot appeared in one of four corners of a grid with an arrow in the middle of the grid (mean inter-trial interval $2.4 \mathrm{~s}$ ). If the central arrow was horizontal, the participant had to indicate whether the target was on the left or right side of the grid (left or right button); if the central arrow was vertical, the participant had to indicate whether the target was in the lower or upper half of the grid (up or down button). During switch trials (21\%) the central arrow changed position, which occurred after every four to six repeat trials $(79 \%)$. The event-related fMRI analysis subtracted activation associated with repeat trials from activation associated with switch trials (switch minus repeat). ${ }^{7}$

Performance was compared between groups using independent $t$-tests on all major task variables. Probability values were adjusted for multiple testing using the false discovery rate. ${ }^{15}$

\section{Image acquisition and analysis}

Gradient-echo echoplanar magnetic resonance imaging data were acquired on a GE Signa $1.5 \mathrm{~T}$ Horizon LX System (General Electric, Milwaukee, Wisconsin, USA) at the Maudsley Hospital, London. A quadrature birdcage head coil was used for radiofrequency transmission and reception. In each of 16 non-contiguous planes parallel to the anterior-posterior commissure, $T_{2}$-weighted MR images depicting blood oxygen level dependent (BOLD) contrast covering the whole brain were acquired, with time to echo (TE) $40 \mathrm{~ms}$, repetition time (TR) $1.8 \mathrm{~s}$ for the Stroop and stop tests and $2.4 \mathrm{~s}$ for the switch test, flip angle $90^{\circ}$, in-plane resolution $3.1 \mathrm{~mm}$, slice thickness $7 \mathrm{~mm}$, slice-skip $0.7 \mathrm{~mm}$. A high-resolution inversion recovery echoplanar image of the whole brain was acquired in the intercommissural plane with $\mathrm{TE}=40 \mathrm{~ms}$, inversion time $(\mathrm{TI})=180 \mathrm{~ms}, \mathrm{TR}=16 \mathrm{~s}$, in-plane resolution $1.5 \mathrm{~mm}$, slice thickness $3 \mathrm{~mm}$, slice-skip $0.3 \mathrm{~mm}$. This imaging data-set provided almost complete brain coverage. Time series analysis for each individual was based on a previously published wavelet-based data resampling method for fMRI data. ${ }^{16}$ Using rigid body and affine transformation, the individual maps were registered into Talairach standard space. ${ }^{17} \mathrm{~A}$ generic brain activation map was then produced for each experimental condition and hypothesis testing was carried out at the cluster level, shown to give excellent cluster-wise type I error control in structural and fMRI analysis. ${ }^{16}$ For each task, fewer than one false-positive activated cluster was expected at a probability value of $P<0.05$ at the voxel level and $P<0.0075$ at the cluster level. Analysis of variance for between-group differences was conducted using randomisation-based testing for voxel- or cluster-wise differences, as described in detail by Bullmore et al. ${ }^{16}$ For this particular group comparison, fewer than one false-activated cluster was expected at a probability value of $P<0.05$ for voxel and $P<0.01$ for cluster comparisons.

\section{Results}

There was no significant difference between the OCD and control groups in measures of IQ, age, handedness, anxiety and depression at the time of scanning (Table 1).

\section{Task performance}

No significant between-group difference was observed for any of the main performance variables. There was a trend, however, for participants with OCD to show increased error rates in the switch and motor Stroop tasks (Table 2).

\section{Brain activation}

\section{Stop task}

In the comparison of successful minus unsuccessful stop trials, the boys in the control group activated right and left orbital prefrontal cortex reaching into superior temporal pole, bilateral precentral gyri, right caudate, thalamus and precuneus. Boys with OCD showed no significant brain activation at this particular threshold. At a more lenient threshold (cluster level of $P<0.05$ ), boys with OCD showed activation in the cerebellum, left superior temporal lobe, right inferior temporal lobe, occipital lobe and premotor cortex. Analysis of variance showed decreased brain activation in the OCD group compared with the control group in the right and left orbitofrontal cortex and in an extensive cluster of right thalamus and the basal ganglia including the head of the caudate, putamen and globus pallidus (Table 3, Fig. 1).

During the comparison of unsuccessful stop-go trials, boys in the control group activated mesial frontal cortex bordering anterior cingulate gyrus, right superior and left middle temporal gyri, and precuneus. The boys with OCD activated right orbitofrontal cortex, left medial temporal and posterior cingulate gyri. Analysis of variance showed decreased activation for the OCD group compared with the control group in the mesial frontal gyrus, reaching laterally into left dorsolateral prefrontal cortex and ventrally into anterior cingulate gyrus (see Table 3, Fig. 1).

\section{Motor Stroop task}

During the comparison of successful incongruent minus congruent trials, boys in the control group showed brain activation in right medial and inferior temporal gyri, in right posterior 
Table 1 Sample characteristics and symptom scores

\begin{tabular}{|c|c|c|c|c|c|c|}
\hline & \multicolumn{2}{|c|}{ OCD group } & \multicolumn{2}{|c|}{ Control group } & \multirow[b]{2}{*}{$t(\mathrm{~d} \cdot \mathrm{f} .=17)^{\mathrm{a}}$} & \multirow[b]{2}{*}{$P$} \\
\hline & Mean (s.d.) & Range & Mean (s.d.) & Range & & \\
\hline WISC verbal performance index & $102(20)$ & $78-140$ & $108(14)$ & $89-125$ & -0.75 & 0.46 \\
\hline Handedness score & $85(32)$ & $30-100$ & $86(11)$ & $65-100$ & -0.15 & 0.89 \\
\hline Age, years & $14.3(1.7)$ & $12-17$ & $14.5(1.1)$ & $12-16$ & -0.26 & 0.80 \\
\hline Anxiety score (R-CMAS) & $8.6(6.4)$ & $0-19$ & $5.33(2.6)$ & 3-11 & 1.41 & 0.18 \\
\hline Depression score (Birleson) & $7.8(5.1)$ & $0-15$ & $7.22(3.3)$ & $2-12$ & 0.29 & 0.78 \\
\hline Duration of OCD, months & 37.7 (19) & $12-78$ & & & & \\
\hline \multicolumn{7}{|l|}{ CY-BOCS scores at diagnosis } \\
\hline Obsession & $10.6(5.7)$ & $2-19$ & & & & \\
\hline Compulsion & $10.1(6.6)$ & $2-22$ & & & & \\
\hline Total score & $20.5(8.3)$ & $12-33$ & & & & \\
\hline \multicolumn{7}{|l|}{ CY-BOCS scores at scanning } \\
\hline Obsession & $5.8(3.6)$ & $0-12$ & & & & \\
\hline Compulsion & $5.2(3.9)$ & $0-10$ & & & & \\
\hline Total score & $11(6.8)$ & $2-21$ & & & & \\
\hline
\end{tabular}

cingulate and precuneus, and in the cerebellum. Boys with OCD showed activation in left and right medial temporal gyri and in the left inferior parietal cortex. Analysis of variance showed significantly decreased activation in the latter group in the right and left cerebellar vermis and right middle temporal gyrus (Table 3, Fig. 1).

\section{Switch task}

For the contrast of successful switch minus repeat trials, boys in the control group showed activation in right inferior parietal lobe reaching rostrally into precentral gyrus, in left inferior parietal lobe, in left and right superior temporal lobes and in midcingulate gyrus. Boys with OCD showed brain activation in the right temporo-occipital lobe. Analysis of variance showed decreased brain activation in the OCD group compared with the control group in right and left inferior parietal and superior temporal cortices which in the right hemisphere reached rostrally into precentral and inferior prefrontal cortices. There was furthermore reduced activation in the OCD group in bilateral vermis and the right hemisphere of the cerebellum (Table 3, Fig. 1).
There was no increased brain activation in the OCD group compared with the control group in any of the tasks.

\section{Discussion}

Despite equivalent task performance, boys with treated OCD in partial remission showed reduced brain activation in task-relevant neural networks during three different inhibition tasks. During the 'stop' task, the boys with OCD showed reduced activation in inferior and orbital frontostriatothalamic brain regions. Stop failures were associated with reduced activation in the OCD group in mesial and dorsolateral prefrontal cortex, including the anterior cingulate gyrus. During the more cognitive inhibition tasks the OCD group showed reduced activation in inferior frontal (switch task) and temporoparietocerebellar regions (motor Stroop and switch tasks). These preliminary findings only partially confirm the hypothesis of abnormal frontostriatothalamic pathways during inhibitory control in paediatric patients with OCD. The findings confirm frontostriatal network abnormalities during motor response inhibition, but in addition show that tasks requiring

Table 2 Performance data for the two study groups

\begin{tabular}{|c|c|c|c|c|c|c|}
\hline & \multicolumn{2}{|c|}{ OCD group } & \multicolumn{2}{|c|}{ Control group } & \multirow[b]{2}{*}{ Mann-Whitney $U$-test ${ }^{a}$} & \multirow[b]{2}{*}{$P^{\mathrm{b}}$} \\
\hline & Mean (s.d.) & Range & Mean (s.d.) & Range & & \\
\hline \multicolumn{7}{|l|}{ Stop task } \\
\hline Inhibition, \% & $47.3(7.1)$ & 40-63 & $51.7(8.1)$ & 40-65 & 39 & NS \\
\hline $\mathrm{SSRT}, \mathrm{ms}^{\mathrm{c}}$ & $238.0(259.8)$ & $189-622$ & $219.4(266.9)$ & $153-613$ & 43 & NS \\
\hline MRT (go trials), ms & $843.0(160.4)$ & $656-1196$ & $819.4(177.0)$ & 655-1231 & 40 & NS \\
\hline \multicolumn{7}{|l|}{ Switch task } \\
\hline Switch cost, $\mathrm{ms}^{\mathrm{d}}$ & $112.7(60.6)$ & $46-262$ & $100.5(54.7)$ & 29-188 & 41.5 & NS \\
\hline Errors to switch trials, \% & $8.4(7.2)$ & $0-22$ & $3.5(4.0)$ & $0-9$ & 25 & 0.095 \\
\hline \multicolumn{7}{|l|}{ Motor Stroop task } \\
\hline Stroop effect, $\mathrm{ms}^{\mathrm{e}}$ & $152.4(88.9)$ & $58-388$ & $122.4(49.6)$ & 63-197 & 36 & NS \\
\hline Stroop errors, \% & $29.2(22.7)$ & 4-75 & $13.0(9.6)$ & $0-25$ & 26.5 & NS \\
\hline \multicolumn{7}{|c|}{$\begin{array}{l}\text { MRT, mean reaction time; NS, not significant; OCD, obsessive-compulsive disorder; SSRT, stop signal reaction time. } \\
\text { a. Between-group comparisons. } \\
\text { b. Adjusted using the false discovery rate. } \\
\text { c. MRT go - stop signal delay. } \\
\text { d. MRT switch - MRT repeat trials. } \\
\text { e. MRT incongruent - MRT congruent trials. }\end{array}$} \\
\hline
\end{tabular}




\begin{tabular}{|c|c|c|c|c|c|c|c|c|}
\hline \multirow[b]{2}{*}{ Task $^{1}$} & \multirow[b]{2}{*}{ Region } & \multirow[b]{2}{*}{ Brodmann area } & \multicolumn{3}{|c|}{ Talairach coordinates } & \multirow[b]{2}{*}{ No. of voxels } & \multirow[b]{2}{*}{$P$} & \multirow[b]{2}{*}{$F$} \\
\hline & & & $x$ & $y$ & $z$ & & & \\
\hline \multirow{4}{*}{$\begin{array}{l}\text { Stop task } \\
\text { (successful stop - } \\
\text { unsuccessful stop) }\end{array}$} & R orbital frontal gyrus & 47 & 29 & 26 & -2 & 47 & 0.00956 & 8.9 \\
\hline & R orbital frontal gyrus & 47 & 43 & 15 & -13 & 47 & 0.00625 & 10.0 \\
\hline & L orbitofrontal/superior temporal gyri & $47 / 38$ & -47 & 11 & -13 & 62 & 0.00574 & 10.7 \\
\hline & $\begin{array}{l}\text { R thalamus/caudate/putamen/ } \\
\text { globus pallidus/insula }\end{array}$ & - & 11 & -11 & -2 & 133 & 0.00211 & 12.8 \\
\hline \multirow{2}{*}{$\begin{array}{l}\text { Stop task } \\
\text { (unsuccessful stop - go trials) }\end{array}$} & R mesial/dorsolateral frontal gyrus & $9 / 10 / 32$ & 4 & 48 & 31 & 242 & 0.00185 & 10.7 \\
\hline & L medial temporal gyrus & 21 & -61 & -15 & -2 & 110 & 0.00507 & 11.8 \\
\hline \multirow[t]{5}{*}{$\begin{array}{l}\text { Switch task } \\
\text { (switch - repeat) }\end{array}$} & $\begin{array}{l}\text { R inferior frontal/premotor/superior } \\
\text { temporal lobe/insula }\end{array}$ & $45 / 6 / 22 / 40$ & 54 & -19 & 31 & 250 & 0.00164 & 10.4 \\
\hline & $\mathrm{R}$ inferior parietal lobe & 40 & 43 & -37 & 42 & 34 & 0.00956 & 11.8 \\
\hline & L inferior parietal/superior temporal lobe & $40 / 42$ & -51 & -19 & 31 & 144 & 0.00384 & 10.1 \\
\hline & R cerebellum hemisphere & - & 29 & -48 & -24 & 74 & 0.00937 & 6.9 \\
\hline & $R$ and $L$ cerebellum vermis & - & 0 & -41 & -24 & 101 & 0.00648 & 7.6 \\
\hline \multirow{2}{*}{$\begin{array}{l}\text { Motor Stroop task } \\
\text { (incongruent - } \\
\text { congruent) }\end{array}$} & R middle/superior temporal gyrus/insula & $21 / 38$ & 43 & -22 & -13 & 108 & 0.00645 & 12.0 \\
\hline & $\mathrm{L}$ cerebellum vermis & - & -7 & -85 & -25 & 214 & 0.00307 & 12.7 \\
\hline $\begin{array}{l}L \text {, left; } R \text {, right. } \\
\text { a. Analysis of variance significance }\end{array}$ & (1) & & & & & & & \\
\hline
\end{tabular}
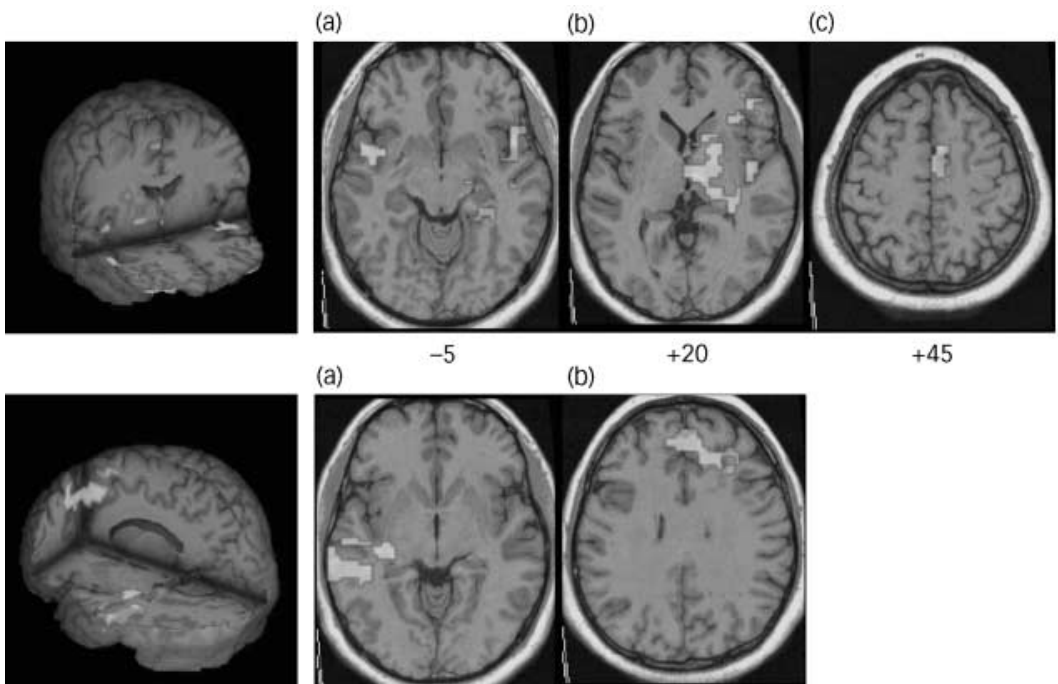

$+45$
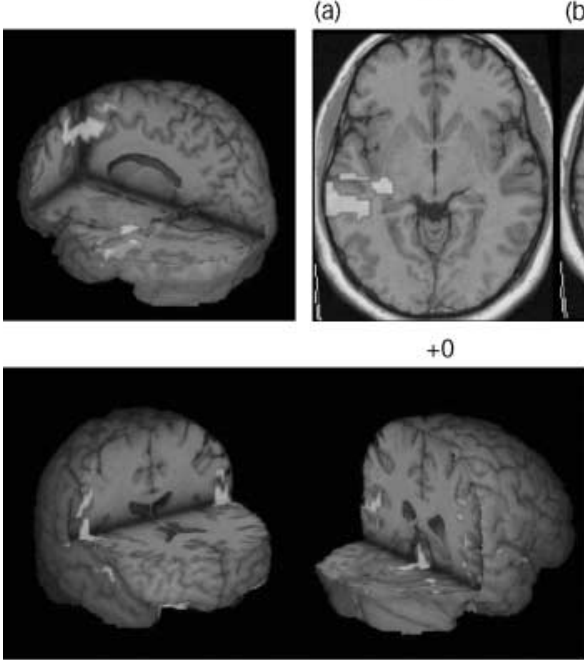

$+25$
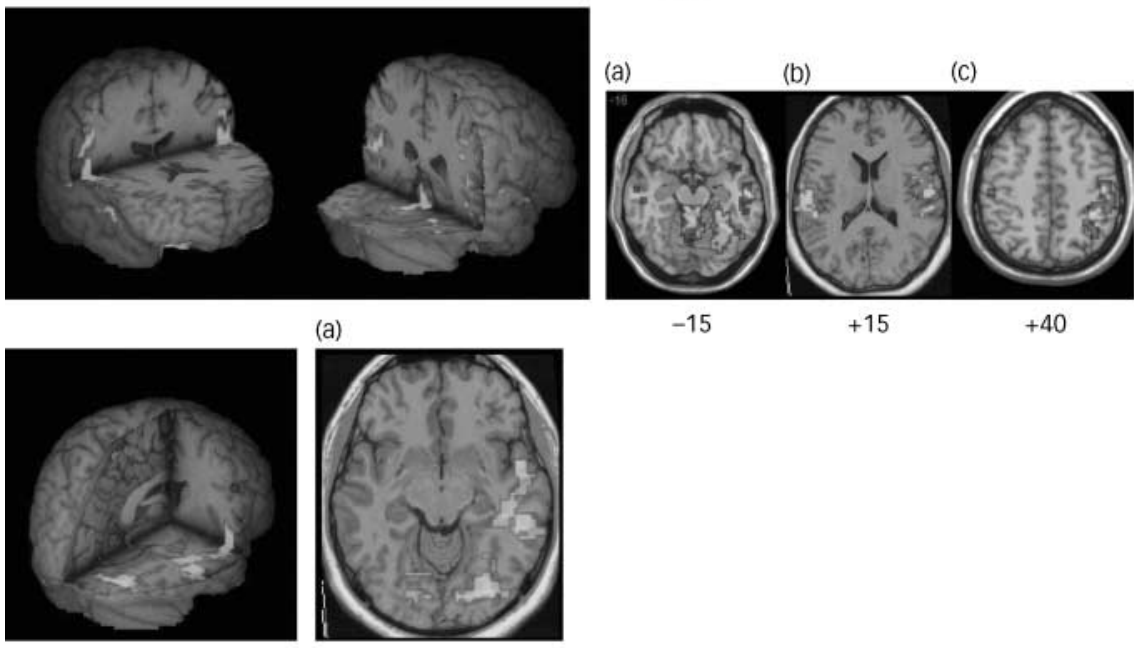

$-15$

$+15$

$+40$

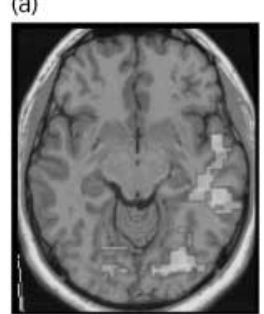

$-5$

Fig. 1 Three-dimensional figures and selected two-dimensional axial slices showing the brain regions of decreased activation $(P<0.01)$ in boys with obsessive-compulsive disorder compared with healthy boys during the different inhibitory tasks. Talairach $Z$-coordinates are indicated for slice distance (in $\mathrm{mm}$ ) from the intercommissural line. 
more cognitive forms of inhibitory control (such as selective and flexible attention) were associated with abnormal functioning in extra-frontal temporal, parietal and cerebellar brain regions.

\section{Frontostriatal underactivation during inhibitory functions}

In line with our hypothesis, the participants with OCD showed reduced brain activation in right orbital and inferior prefrontal cortex and striatal and thalamic brain regions during the stop task, areas of typical activation during this task in healthy adolescents and adults in this and previous studies. ${ }^{8,14}$ This finding of frontostriatothalamic underactivation during motor inhibition in young people with OCD supports the hypothesis that a dysregulation of orbitofrontostriatal pathways mediating inhibitory control functions underlies the pathology of this disorder. The findings are also in line with reported structural and biochemical abnormalities in paediatric OCD in the frontal lobes, basal ganglia and thalamus, ${ }^{18,19}$ which have been shown to correlate with severity of OCD symptoms. ${ }^{20}$ In adults, correlations between orbitofrontal dysfunction, structural abnormalities and OCD symptoms have been observed, ${ }^{21}$ which, interestingly, were more pronounced in patients with early-onset OCD. ${ }^{22}$

The right inferior prefrontal cortex was also underactivated in the OCD group in the switch task, an area that has been found in previous studies to mediate inhibition of irrelevant stimulusresponse associations during task switching. ${ }^{7}$ Similar to these results are findings of a correlation between abnormal blood flow in left inferior prefrontal cortex and errors on the Wisconsin Card Sorting Task switching task in adult OCD. ${ }^{23}$ Differences in switch task design or age groups might have resulted in the laterality differences of findings between the present study and that of Lucey et al (1997).

Stop task failures were associated with underactivation in the OCD group in mesial and dorsolateral prefrontal cortices, two interrelated brain regions that have been suggested to synergistically mediate performance monitoring and error detection. ${ }^{24}$ Mesial frontal cortex, especially anterior cingulate gyrus, has been shown to be biochemically ${ }^{25}$ and structurally abnormal in children with OCD,${ }^{19}$ whereas abnormal neurochemical markers have been found in left dorsolateral prefrontal cortex. Dysfunction of these two interconnected brain regions in the context of errors supports the view of a neurocognitive dysregulation of performance monitoring functions in OCD. ${ }^{26,27}$

Although the brain areas of dysfunction in this study are also consistent with brain regions that have been found to be abnormal in neurochemical, morphological and functional imaging findings in adult OCD, ${ }^{3,28,29}$ the specific finding of underactivation of these brain regions during cognitive challenge is only partly in line with adult functional imaging studies. Reduced activation in caudate has been observed in adults with OCD during implicit learning, ${ }^{30}$ in the caudate and dorsolateral prefrontal cortex during planning, ${ }^{31}$ and in the dorsolateral prefrontal cortex and anterior cingulate gyrus during a colour-word Stroop task. ${ }^{5}$ Other studies, however, have found overactivation in adult OCD during cognitive tasks, most consistently in the anterior cingulate in the context of performance monitoring or conflict detection, ${ }^{4,26,27}$ but also during inhibition and planning. ${ }^{26,31}$ Differences between adult and childhood OCD could account for differences in findings. Early-onset $\mathrm{OCD}$ has been shown to differ from the late-onset disorder, with the former showing reduced blood flow in the bilateral inferior prefrontal cortex, right thalamus and anterior cingulate gyrus, ${ }^{22}$ areas we have found to be reduced in their function in this sample of paediatric patients with OCD. Findings in this population might be less influenced by the effects of chronicity or long-term medication compared with adults with the disorder, and may represent a more homogeneous sample. Over time, adults with OCD may compensate for chronic frontostriatal dysfunction, possibly by overactivating the performance monitoring system of the brain mediated by anterior cingulate and lateral prefrontal brain regions. This would be supported by the findings of van den Heuvel et al of both decreased lateral frontostriatal and increased anterior cingulate activation in adult OCD during poor planning performance. ${ }^{31}$ The adolescents with OCD recruited to this study were in partial remission and had relatively few symptoms of the disorder, in contrast to the published adult studies in which patients were fully symptomatic. The increased anterior cingulate activation seen in the adult studies might be more related to active obsessive-compulsive symptoms rather than representing a marker of trait brain differences in individuals with OCD.

The findings of underactivation in frontostriatal pathways during cognitive challenge in paediatric OCD is also interesting in view of relatively consistent findings of overactivation of the same brain regions during symptom provocation in adult OCD. ${ }^{28}$ It has been argued that chronic overactivation of frontostriatothalamic pathways that are responsible for obsessive and compulsive symptoms would make the brain regions involved in these pathways less recruitable for cognitive functions, which would explain concurrent underactivation of the symptom-related reduced frontostriatal pathways during cognitive challenge. This is in line with a study showing that pharmacological treatment in adult OCD leads to a reduction of previously increased frontostriatal activation with a symptom provocation task, whereas it increased previously reduced frontal activation in a Stroop task. ${ }^{5}$

\section{Underactivation in temporoparietal and cerebellar regions}

The underactivation in adolescents with OCD in parietal, temporal and cerebellar cortices during the motor Stroop and switch tasks was unexpected and may be related to the high load on parietotemporal activation during these tasks, presumably related to visuospatial attention mechanisms. ${ }^{7}$ The motor Stroop and switch tasks measure more cognitive forms of inhibition compared with the stop task and have a higher load on selective attention functions. The underactivation in participants with OCD of frontoparietotemporal and cerebellar brain regions during these tasks might thus be related to problems with attentional rather than inhibitory networks. Deficits in selective attention and cognitive flexibility, not just inhibitory functions, have been found in adult patients with OCD. ${ }^{1,2}$ Furthermore, evidence exists in adult OCD for structural and functional abnormalities in temporal, parietal and cerebellar brain regions. ${ }^{28,29}$ with increased functioning in these regions if symptoms improve. ${ }^{5}$ The findings thus suggest task-specific abnormalities in paediatric OCD that are not limited to frontostriatal pathways but extend to frontotemporoparietal and frontocerebellar networks.

\section{Unimpaired task performance}

The findings of unimpaired performance on tasks of inhibitory control in adolescents with OCD contrast with findings in adult OCD of deficits during similar and even identical tasks of motor inhibition, interference inhibition and cognitive switching. ${ }^{1,2}$ However, the number of participants in our study is small for neuropsychological analysis, and generalisations cannot be made. Group differences might have emerged with larger sample sizes, especially in the motor Stroop and switch tasks where a trend towards impairment was observed. Two additional possible 
explanations for the absence of between-group performance differences are, first, that the patients included in this study were treated and had OCD at low symptom levels, and second, that the fMRI adaptations of cognitive tasks are usually easier to perform, and therefore lose a degree of behavioural sensitivity. The lack of performance differences, therefore, should be considered a preliminary finding and the relationship between brain and behavioural abnormalities needs to be addressed in future, larger-scale fMRI studies in children with fully symptomatic OCD.

\section{Brain abnormalities in inhibitory networks: a trait marker of OCD?}

Given the partially remitted nature of the disorder in our OCD group, these preliminary findings of dysfunction in neural networks of inhibition and attention are likely to reflect a trait marker of OCD. The advantage of scanning patients with low symptom levels is that findings are less likely to be confounded by anxiety and the potential need to inhibit obsessions and compulsions in the scanner. However, this also limits the generalisability of findings. Brain abnormalities in fully symptomatic patients are likely to be larger or different. Future fMRI studies in larger samples of paediatric patients with fully symptomatic OCD are needed to investigate whether the brain abnormalities in these children resemble those in adult patients.

\section{Limitations}

Limitations of this study are in particular the small sample size and the fact that $80 \%$ of patients were medicated with an SSRI. Little is known about the effects of SSRIs on functional brain activation patterns, although there is some evidence to suggest they may increase specific regional relative metabolic rate, but with different effects depending on duration of administration. ${ }^{32}$ In adult OCD, medication with SSRIs has been shown to reduce symptom-related overactivation in frontal and striatal brain regions but increase task-relevant brain activation during cognitive challenge. ${ }^{5}$ This implies that medication may have a mitigating effect on brain dysfunction, which might have been more pronounced in medication-naïve adolescents with OCD.

In conclusion, this preliminary fMRI study provides the first evidence that paediatric OCD in remission is characterised by dysfunctions of frontostriatothalamic networks during motor inhibition, and of frontotemporoparietal cortices and cerebellum during the more attentional cognitive inhibition tasks. An underlying neurocognitive deficit in brain regions mediating inhibitory and attention functions may be a predisposing factor to the emergence of obsessions and compulsions, the characteristic symptoms of OCD.

\footnotetext{
James Woolley, MRCP, MRCPsych, Section of Neuroimaging, Isobel Heyman, $\mathrm{PhD}$, MRCPsych, Child and Adolescent Psychiatry, Mick Brammer, PhD, Brain Image Analysis Unit, Ian Frampton, DClinPsych, Child and Adolescent Psychiatry, Philip K. McGuire, MD, PhD, FRCPsych, Section of Neuroimaging, Katya Rubia, $\mathrm{PhD}$, Child and Adolescent Psychiatry, Institute of Psychiatry, London, UK

Correspondence: Dr Katya Rubia, Child and Adolescent Psychiatry (PO 46), Institute of Psychiatry, Denmark Hill, London SE5 8AF, UK. Email: k.rubia@iop.kcl.ac.uk

First received 2 February 2007, final revision 18 July 2007, accepted 7 September 2007
}

\section{Acknowledgements}

Drs Cath Caulfield, Catherine Mortimore and Mark Hutchinson performed the psychological testing of the participants. The work was supported by the PPP Foundation (grant number 1206/1568)

\section{References}

1 Chamberlain SR, Fineberg NA, Blackwell AD, Robbins TW, Sahakian BJ. Motor inhibition and cognitive flexibility in obsessive-compulsive disorder and trichotillomania. Am J Psychiatry 2006; 163: 1282-4.

2 Penadés R, Catalán R, Rubia K, Andrés S, Salamero M, Gastó C. Impaired response inhibition in obsessive compulsive disorder. Eur Psychiatry 2007; 22: 404-10.

3 Graybiel AM, Rauch SL. Toward a neurobiology of obsessive-compulsive disorder. Neuron 2000; 28: 343-7.

4 Viard A, Flament MF, Artiges E, Dehaene S, Naccache L, Cohen D, Mazet P, Mouren MC, Martinot JL. Cognitive control in childhood-onset obsessivecompulsive disorder: a functional MRI study. Psychol Med 2005; 35: 1007-17.

5 Nakao T, Nakagawa A, Yoshiura T, Nakatani E, Nabeyama M, Yoshizato C, Kudoh A, Tada K, Yoshioka K, Kawamoto M. A functional MRI comparison of patients with obsessive-compulsive disorder and normal controls during a Chinese character Stroop task. Psychiatry Res 2005; 139: 101-14.

6 Pauls D, Alsobrook J, Goodman W, Rasmussen S, Leckman J. A family study of obsessive compulsive disorder. Am J Psychiatry 1995; 152: 76-84.

7 Rubia K, Smith AB, Woolley J, Nosarti C, Heyman I, Taylor E, Brammer M. Progressive increase of frontostriatal brain activation from childhood to adulthood during event-related tasks of cognitive control. Hum Brain Mapp 2006; 27: 973-93.

8 Rubia K, Smith A, Taylor E, Brammer M. Linear age-correlated functional development of right inferior fronto-striato-cerebellar network during response inhibition and anterior cingulate during error-related processes. Hum Brain Mapp 2007; 28: 1163-77.

9 Nielen MM, Den Boer JA. Neuropsychological performance of OCD patients before and after treatment with fluoxetine: evidence for persistent cognitive deficits. Psychol Med 2003; 33: 917-25.

10 Scahill L, Riddle MA, McSwiggin-Hardin M, Ort SI, King RA, Goodman WK, Cicchetti D, Leckman JF. Children's Yale-Brown Obsessive Compulsive Scale: reliability and validity. J Am Acad Child Adolesc Psychiatry 1997; 36: 844-52.

11 Birleson P. The validity of depressive disorder in childhood and the development of a self-rating scale: a research report. J Child Psychol Psychiatry 1981; 22: 73-88.

12 Reynolds C, Richmond B. What I think and feel: a revised measure of children's manifest anxiety. J Abnorm Child Psychol 1978; 6: 271-80.

13 Achenbach TM, Edelbrock CS. Manual for the Child Behavior Checklist and Revised Child Behavior Profile. University of Vermont, 1983.

14 Rubia K, Smith AB, Brammer MJ, Taylor E. Right inferior prefrontal cortex mediates response inhibition while mesial prefrontal cortex is responsible for error detection. Neuroimage 2003; 20: 351-8.

15 Benjamini $Y$, Hochberg $Y$. Controlling the false discovery rate: a practical and powerful approach to multiple testing. J R Stat Soc Ser B: Methodol 1995; 57: 289-300.

16 Bullmore ET, Suckling J, Overmeyer S, Rabe-Hesketh S, Taylor E, Brammer MJ. Global, voxel, and cluster tests, by theory and permutation, for a difference between two groups of structural MR images of the brain. IEEE Trans Med Imaging 1999; 18: 32-42.

17 Talairach J, Tournoux P. Co-Planar Stereotaxic Atlas of the Human Brain. Thieme, 1988.

18 Rosenberg DR, Keshavan MS, O'Hearn KM, Dick EL, Bagwell WW, Seymour $A B$, Montrose DM, Pierri JN, Birmaher B. Frontostriatal measurement in treatment-naive children with obsessive-compulsive disorder. Arch Gen Psychiatry 1997; 54: 824-30.

19 Szeszko PR, MacMillan S, McMeniman M, Chen S, Baribault K, Lim KO, Ivey J Rose M, Banerjee SP, Bhandari R, Moore GJ, Rosenberg DR. Brain structural abnormalities in psychotropic drug-naive pediatric patients with obsessivecompulsive disorder. Am J Psychiatry 2004; 161: 1049-56.

20 Gilbert AR, Moore GJ, Keshavan MS, Paulson LA, Narula V, MacMaster FP, Stewart CM, Rosenberg DR. Decrease in thalamic volumes of pediatric patients with obsessive-compulsive disorder who are taking paroxetine. Arch Gen Psychiatry 2000; 57: 449-56.

21 Pujol J, Soriano-Mas C, Alonso P, Cardoner N, Menchón JM, Deus J, Vallejo J. Mapping structural brain alterations in obsessive-compulsive disorder. Arch Gen Psychiatry 2004; 61: 720-30.

22 Rosario-Campos MC, Leckman JF, Mercadante MT, Shavitt RG, Prado HS, Sada P, Zamignani D, Miguel EC. Adults with early-onset obsessivecompulsive disorder. Am J Psychiatry 2001; 158: 1899-903.

23 Lucey JV, Burness CE, Costa DC, Gacinovic S, Pilowsky LS, Ell PJ, Marks IM, Kerwin RW. Wisconsin Card Sorting Task (WCST) errors and cerebral blood flow in obsessive-compulsive disorder (OCD). Br J Med Psychol 1997; 70: 403-11. 
24 Ridderinkhof KR, Ullsperger $M$, Crone EA, Nieuwenhuis $S$. The role of the medial frontal cortex in cognitive control. Science 2004; 306: 443-7.

25 Rosenberg DR, Mirza Y, Russell A, Tang J, Smith JM, Banerjee SP, Bhandari R, Rose M, Ivey J, Boyd C, Moore GJ. Reduced anterior cingulate glutamatergic concentrations in childhood OCD and major depression versus healthy controls. J Am Acad Child Adolesc Psychiatry 2004; 43: 1146-53.

26 Ursu S, Stenger VA, Shear MK, Jones MR, Carter CS. Overactive action monitoring in obsessive-compulsive disorder: evidence from functional magnetic resonance imaging. Psychol Sci 2003; 14: 347-53.

27 Maltby N, Tolin DF, Worhunsky P, O'Keefe TM, Kiehl KA. Dysfunctional action monitoring hyperactivates frontal-striatal circuits in obsessive-compulsive disorder: an event-related fMRI study. Neuroimage 2005; 24: 495-503.

28 Whiteside SP, Port JD, Abramowitz JS. A meta-analysis of functional neuroimaging in obsessive-compulsive disorder. Psychiatry Res 2004; 132 69-79.
29 Kim JJ, Lee MC, Kim J, Kim IY, Kim SI, Han MH, Chang KH, Kwon JS. Grey matter abnormalities in obsessive-compulsive disorder: statistical parametric mapping of segmented magnetic resonance images. Br J Psychiatry 2001; 179: $330-4$.

30 Rauch SL, Savage CR, Alpert NM, Dougherty D, Kendrick A, Curran T, Brown HD, Manzo P, Fischman AJ, Jenike MA. Probing striatal function in obsessivecompulsive disorder: a PET study of implicit sequence learning. $J$ Neuropsychiatry Clin Neurosci 1997; 9: 568-73.

31 van den Heuvel OA, Veltman DJ, Groenewegen HJ, Cath DC, van Balkom AJ, van Hartskamp J, Barkhof F, van Dyck R. Frontal-striatal dysfunction during planning in obsessive-compulsive disorder. Arch Gen Psychiatry 2005; 62: 301-9.

32 Gerdelat-Mas A, Loubinoux I, Tombari D, Rascol O, Chollet F, SimonettaMoreau M. Chronic administration of selective serotonin reuptake inhibitor (SSRI) paroxetine modulates human motor cortex excitability in healthy subjects. Neuroimage 2005; 27: 314-22.

\section{Word pictures of depression: thoughts of death}

\section{Sharon Mcconville}

As I descended more deeply into my depression, I became increasingly preoccupied with thoughts and images of death, to the extent that other subjects seemed meaningless. These thoughts often translated into vivid dreams . .

'Despair was my foremost emotion during the night which has just passed. I awoke at 3 am from a sleep plagued with unremembered nightmares, my muscles tensed for fight or flight, my mind preoccupied with poorly-developed but unquestionably negative thoughts. I felt like I was lying in the middle of a scene from a scary movie, one of those suspense thrillers where the colours of the shots are murky and the soundtrack is distorted so that it sounds like it is being heard through water, its chords bending and smouldering out, somehow making you suspect that an ominous, unseen presence is about to manifest itself: listening to it makes you want to look over your shoulder to check that no one is following you, but makes you afraid to do so in case someone-or something - surprises you from the front. I suppose this experiential phenomenon could be described as paranoia or possibly 'free-floating anxiety'; whatever the terminology, it was unpleasant. I got up eventually and told [the night nurses] - who were both engrossed in reading material, [one] studying a psychology textbook, [the other] a celebrity magazine - how I was feeling. Somehow I needed to share my feelings to help me confirm that they were not real. They made me some herbal tea and I went back to bed much reassured. Then, just as I crawled under the heavy covers, images began to flood my brain. First there was a coffin, a funeral procession, my mother crying. Then there was a wake: faceless people surrounding a white-robed figure lying in an open casket. I recognised this figure. It did not physically resemble me but I knew that it represented me, just as I had earlier been dreaming about events which I knew were unfolding in Belfast even though the physical surroundings were more consistent with Edinburgh (the hilltop castle and shops of Princess Street were prominent in the background scenery). I could not escape this morbid preoccupation, no doubt related as much to the fact that Mum and Dad had been discussing my Great Aunt Ina's funeral with me yesterday as much as my own thoughts about suicide. However, it was the risk of self-harm which concerned [the nurse] most when I visited her once again to de-escalate my feelings by sharing them with her. "You've had a traumatic week, Sharon. It's not surprising that your sleep is disturbed with such thoughts floating around in your head. Please, please come back and speak to us at any time that you need to: that's what we're here for. You don't need to cope with this on your own." I still felt anxious when I returned again to bed but I managed to calm myself enough to fall eventually into an un-refreshing, tossing-and-turning slumber. I do not know if I dreamt again after that. I was glad though, when morning came. 